\title{
EVALUATION OF WOOD-BASED COATING PERFORMANCE FOR ULTRAVIOLET ROLLER AND CONVENTIONAL AIR-ATOMIZATION PROCESSES
}

\author{
Ender Hazir ${ }^{1,4}$ \\ https://orcid.org/0000-0002-8998-4450 \\ Kucuk Huseyin Koc ${ }^{l}$ \\ https://orcid.org/0000-0001-6370-2016
}

\begin{abstract}
In this study, the effects of two different coating processes on the surface coating performance of wood-based panels were investigated. The samples were prepared using an ultraviolet roller coater and conventional air-atomized systems. Adhesion strength, surface coating hardness, and layer thickness were selected as the coating performance parameters. These coating performance parameters were analyzed using an analysis of variance, Grubb's test, and probability plot. Adhesion strength, surface coating hardness, and layer thickness were measured using the pull-off test, pendulum hardness, and ultrasonic layer thickness, respectively. According to the ANOVA results, the coating process type was the most significant factor on adhesion strength, layer thickness, and surface coating hardness.
\end{abstract}

Keywords: Adhesion strength, atomization coating process, layer hardness, layer thickness, roller coating process, ultraviolet paints.

\section{INTRODUCTION}

Coating applications such as varnish, stain, and paint, are commonly used in the furniture industry. These applications provide enhanced stability, resistance to external influences, and give different appearance features (Sjökvist and Blom 2019). Paint types, such as cellulosic, polyurethane, ultraviolet (UV)-curable, and water-based, provide a protective and decorative appearance for wood and wood-based materials (Gobakken and Westin 2008, Altigen and Militz 2017). Moreover, polyurethane applications provide some properties such as flexibility, abrasion resistance, chemical resistance, good adhesion, fast drying, and yellowing resistance (Bulian and Graystone 2009.) For these reasons, polyurethane paints are widely applied in the furniture industry.

These applications affect wood coating performance such as adhesion strength, UV resistance, layer hardness, abrasion resistance, and layer thickness (Keskin and Tekin 2011, Nejad and Cooper 2011, Sögütlü et al. 2016, Salca et al. 2017, Hazir et al. 2020). The type of coating process is significant in determining the coating type, coating performance, and production planning product (Cool and Hernandez 2011, Landry et al. 2013). Generally, the coating processes are subdivided into two categories: contact and atomizing methods. Contact methods are brushing, padding, dipping, autoclave vacuum with pressure application, roller coating, curtain coating, flow coating, and vacuum coating. Atomizing systems are conventional air-atomized systems, pneumatic-atomization with high air volume and low pressure (HVLP), hydraulic atomization, hydraulic air-assisted atomization, operational aspect of spray application, mechanical atomization, and spray application 
of powder coating (Bulian and Graystone 2009, Hazir 2018). Roller coater and conventional air-atomized systems are especially widely used in the furniture industry. Additionally, there are coating processes in which these two systems are used together. Pneumatic atomization systems are a useful and economic method for the wood coating industry. Roller coater systems are applied for integration of stains (solvent and water-based coatings) and one component coating (primer and top coating). Due to the high amount of solids and the viscosity of the paint used in roller coater applications, it gives better results than atomization systems and the transfer efficiency ratios are better than in atomization systems (Plesniak et al.2004). However, the investment costs of roller coater systems are high and are more suitable for mass production applications. Because the drying time of semi-finished products in roller coater systems is low, the semi-products can be sent to the assembly and brought into the final product quickly. While atomization systems are suitable for both wood and wood-based panels, roller coater operation is more suitable for wood-based panels. Fiberboard and particleboard are widely used in the furniture industry. In particular, medium-density fiberboard (MDF) is used in different woodworking and coating processes (Jocham et al. 2011, Ugulino and Hernandez 2016). Surface quality of MDF depends on various machining processes such as sanding, drilling, and computer numerical control (CNC) machining conditions. Surface quality of MDF with different coating types are important for furniture quality (Ahola 1995, de Moura and Hernandez 2006, Salca et al. 2016, Ramananantoandro et al. 2017, Erdinler et al. 2019). These applications may cause decreased surface coating performance, prevent achievement of the desired surface performance values, and cause an increase in the production costs (Hernandez and Cool 2008, Acda et al. 2012, Nejad et al. 2012, Dilik et al. 2015, Gurleyen et al. 2017).

In this work, MDF samples were coated with both roller coater and atomization processes. Adhesion strength, surface coating hardness, and layer thickness were selected as quality characteristics. These quality characteristics were used to evaluate the surface coating performance.

\section{MATERIAL AND METHODS}

\section{Properties of MDF}

In this study, MDF (Kastamonu Entegre, Istanbul, Turkey) was used as it is of high demand in the furniture industry. The specimens were prepared to a size of $25 \times 40 \times 1,8 \mathrm{~cm}^{3}$. A GreCon DAX 6000 (Fagus-GreCon, Alfeld, Germany) equipment was used to determine the density for MDF. The density mean profile of MDF was $749,59 \mathrm{~kg} / \mathrm{m}^{3}$.

\section{Sanding and coating process}

A numerical controller-based sanding machine was used to prepare the samples (S 211, Biesse Group, Charlotte, NC, USA). The samples were sanded using a feed rate of $5 \mathrm{~m} / \mathrm{min}$, cutting speed of $18 \mathrm{~m} / \mathrm{s}$, grit size of 120 and followed by 150 , belt tension of $3 \mathrm{~kg} / \mathrm{cm}^{2}$, and aluminum oxide sandpaper. After the samples were produced using these sanding parameters, the samples were coated with different coating applications. In the roller coater process, UV acrylic putty (AkzoNobel, Istanbul, Turkey) of $60 \mathrm{~g} / \mathrm{m}^{2}$ was applied to coat the primer finishing process. This process was produced with roller coating and infrared (IR) lamps. Second, specimens were coated with $20 \mathrm{~g} / \mathrm{m}^{2} \mathrm{UV}$ (AkzoNobel, Istanbul, Turkey). Finally, samples were top coated with a polyurethane paint (AkzoNobel, Istanbul, Turkey) using a pneumatic-spray gun applying a pressure of 0,80 $\mathrm{MPa}$ and paint amount of $350 \mathrm{~g} / \mathrm{m}^{2}$.

In the atomization process, polyurethane paint was applied at an amount of $120 \mathrm{~g} / \mathrm{m}^{2}$ to coat the primer coating process. After these coated samples were dried, samples were sanded with 320 to 500 sandpaper and they were top coated a polyurethane paint with a pneumatic-spray gun applying a pressure of $0,80 \mathrm{MPa}$ and paint amount of $350 \mathrm{~g} / \mathrm{m}^{2}$. After these processes were completed, the coated specimens were kept in the temperature conditioning room for $8 \mathrm{~h}$ to $10 \mathrm{~h}$. The properties of the primer, acrylic, and top coating material are given in Table 1. 
Table 1: Properties of ultraviolet acrylic putty, ultraviolet sealer, and polyurethane paints.

\begin{tabular}{|c|c|c|c|}
\hline Material Type & Viscosity $\left(20^{\circ} \mathrm{C}\right)$ & Density $\left(\mathrm{g} / \mathrm{cm}^{3}\right)$ & Solid Content $(\%)$ \\
\hline $\begin{array}{c}\text { UV acrylic } \\
\text { putty }\end{array}$ & 1150 to 1550 poise & 1,62 & 100 \\
\hline UV sealer & $90 \mathrm{~s}$ to $110 \mathrm{~s}$ & 1,07 & 80 \\
\hline Polyurethane & $110 \mathrm{~s}$ to $120 \mathrm{~s}$ & 1,02 & 48 \\
\hline
\end{tabular}

\section{Evaluation of the coating performance}

In this study, coating strength performance was determined via a pull-off test method in accordance with TS EN ISO 4624 (2016). Steel dollies with 20-mm diameter were glued onto the painted wood surface. This was performed in ambient conditions of $20^{\circ} \mathrm{C}$ and $40 \%$ relative humidity (RH). Samples of coating hardness were determined following the TS EN ISO 1522 (2005) standard. Pendulum hardness equipped with a Konig pendulum apparatus were applied to perform the coating hardness. Dry film thickness is another important quality characteristic for applied paint amount. The dry layer thicknesses of the samples were measured using a PosiTector (PosiTector 200, DeFelsko, Ogdensburg, NY, USA) with respect to the TS EN ISO 2808 (2019).

\section{Statistical analysis}

To evaluate the adhesion strength, coating hardness, and layer thickness of the samples, 30 measurements were gathered for each quality characteristic and coating process. The Anderson-Darling test was applied to determine if a sample of observed value came from a population with a specific distribution. Grubb's method was applied to analyze the outlier data. It detects one outlier at a time with various probabilities from the observed value with assumed normal distribution. Additionally, effective factors were analyzed with analysis of variance (ANOVA). These analyses were applied Minitab Statistical Software (Minitab 2019).

Analysis of variance with F-test was used to analyze the significance factor on the coating performance. Null hypothesis and F-value are given in Equation 1 and Equation 2, respectively:

$$
\left.\begin{array}{l}
H_{0}: u_{1}=u_{2}=\ldots=u_{\alpha} \\
H_{1}: u_{i} \neq u_{j} \text { for at least one pair }(i, j)
\end{array}\right\}
$$

The F-value was calculated by Equation 2:

$$
F_{0}=\frac{S S_{A} / \alpha-1}{S S_{E} / N-\alpha}=\frac{M S_{A}}{M S_{E}}
$$

The terms $(\alpha-1)$ and $(\mathrm{N}-\alpha)$ are the degrees of freedom and the error degrees of freedom for the parameter $\mathrm{A}$, respectively. The sum squares of means and errors for the variable A are indicated by $M S_{\mathrm{A}}$ and $M S_{\mathrm{E}}$, respectively. The null hypothesis was rejected when the $F_{0}$ was higher than the critical value of $F_{\alpha, \alpha-1, \mathrm{~N}-\alpha, \mathrm{a}}$, where $\alpha$ is the level of the significance.

\section{RESULTS AND DISCUSSION}

The results of adhesion strength, layer thickness, and coating hardness tests for different coating process are given in the Table 2 . For each type of coating process, $(2 \times(30 \times 3))$ data were gathered to process, and these values were analyzed with ANOVA, Grubb's test, probability, and Tukey test. Experiments were performed in random order to reduce the variations that may occur during the experiments. 
Table 2: Coating performance results for different coating process.

\begin{tabular}{|c|c|c|c|c|c|}
\hline \multicolumn{3}{|c|}{ Roller Coating Process } & \multicolumn{3}{|c|}{ Atomization Process } \\
\hline $\begin{array}{c}\text { Adhesion } \\
\text { (MPa) }\end{array}$ & $\begin{array}{l}\text { Hardness } \\
\text { (c) }\end{array}$ & $\begin{array}{c}\text { Thickness } \\
(\mu \mathrm{m})\end{array}$ & $\begin{array}{l}\text { Adhesion } \\
(\mathrm{MPa})\end{array}$ & $\begin{array}{l}\text { Hardness } \\
\text { (c) }\end{array}$ & $\begin{array}{c}\text { Thickness } \\
(\mu \mathrm{m})\end{array}$ \\
\hline 2,50 & 150 & 226,3 & 2,03 & 131 & 147,4 \\
\hline 2,78 & 149 & 231,8 & 1,98 & 140 & 152,7 \\
\hline 2,89 & 149 & 231,3 & 1,75 & 134 & 150,9 \\
\hline 3,16 & 151 & 235,6 & 2,06 & 133 & 153,3 \\
\hline 2,60 & 148 & 234,1 & 2,17 & 124 & 154,7 \\
\hline 3,08 & 151 & 232,3 & 1,74 & 128 & 142,1 \\
\hline 2,57 & 152 & 230,8 & 1,88 & 123 & 159,7 \\
\hline 2,81 & 147 & 232,8 & 1,95 & 122 & 161,4 \\
\hline 2,84 & 149 & 237,9 & 2,13 & 127 & 149,6 \\
\hline 2,72 & 148 & 232,5 & 1,79 & 131 & 154,4 \\
\hline 2,64 & 150 & 231,3 & 1,84 & 129 & 159,5 \\
\hline 2,76 & 150 & 228,7 & 1,91 & 130 & 152,7 \\
\hline 2,85 & 151 & 232,6 & 1,98 & 136 & 151,5 \\
\hline 2,81 & 149 & 235,2 & 2,08 & 128 & 149,7 \\
\hline 2,79 & 147 & 234,6 & 2,31 & 137 & 147,1 \\
\hline 3,09 & 153 & 230,1 & 1,87 & 134 & 145,5 \\
\hline 2,63 & 152 & 234,4 & 2,24 & 132 & 151,3 \\
\hline 2,87 & 149 & 232,0 & 2,18 & 129 & 153,8 \\
\hline 2,73 & 147 & 234,5 & 2,32 & 131 & 148,9 \\
\hline 2,95 & 150 & 232,2 & 2,15 & 130 & 153,6 \\
\hline 2,64 & 154 & 229,6 & 2,22 & 136 & 142,8 \\
\hline 3,12 & 146 & 229,8 & 1,97 & 132 & 146,5 \\
\hline 2,88 & 151 & 236,5 & 2,02 & 134 & 149,7 \\
\hline 3,33 & 147 & 230,0 & 2,31 & 133 & 151,2 \\
\hline 2,96 & 148 & 235,7 & 2,18 & 137 & 152,3 \\
\hline 2,79 & 150 & 231,1 & 1,97 & 129 & 150,6 \\
\hline 2,81 & 148 & 229,1 & 2,00 & 127 & 146,8 \\
\hline 3,39 & 146 & 235,3 & 2,24 & 138 & 149,8 \\
\hline 3,07 & 148 & 227,8 & 2,36 & 125 & 152,3 \\
\hline 2,92 & 147 & 229,7 & 2,38 & 129 & 154,1 \\
\hline
\end{tabular}

\section{Evaluation of adhesion strength, layer thickness, and coating hardness}

Probability plot results of adhesion strength values for different coating processes are shown in Figure 1. The mean, standard deviation (SD), sample size (N), Andersen darling test (AD), and P-critical values are displayed with the probability plot. With respect to the results, as P-value was higher than 0,05 , observed values had a normal distribution. Mean values of the roller coating and atomization processes for adhesion strength were 2,866 MPa and 2,067 MPa, respectively. 


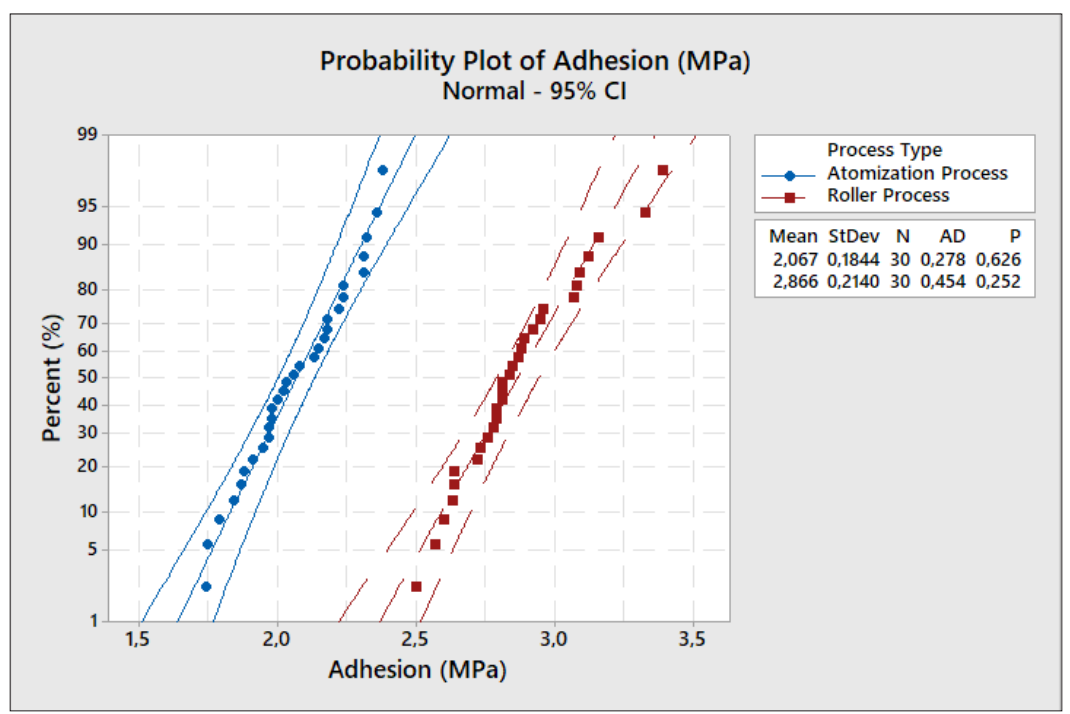

Figure 1: Probability plot results for adhesion strength values.

Probability plot results for layer hardness values for roller and atomization processes are displayed in Figure 2. Roller and atomization process mean values for coating hardness were 149,2 c and $131 \mathrm{c}$, respectively.

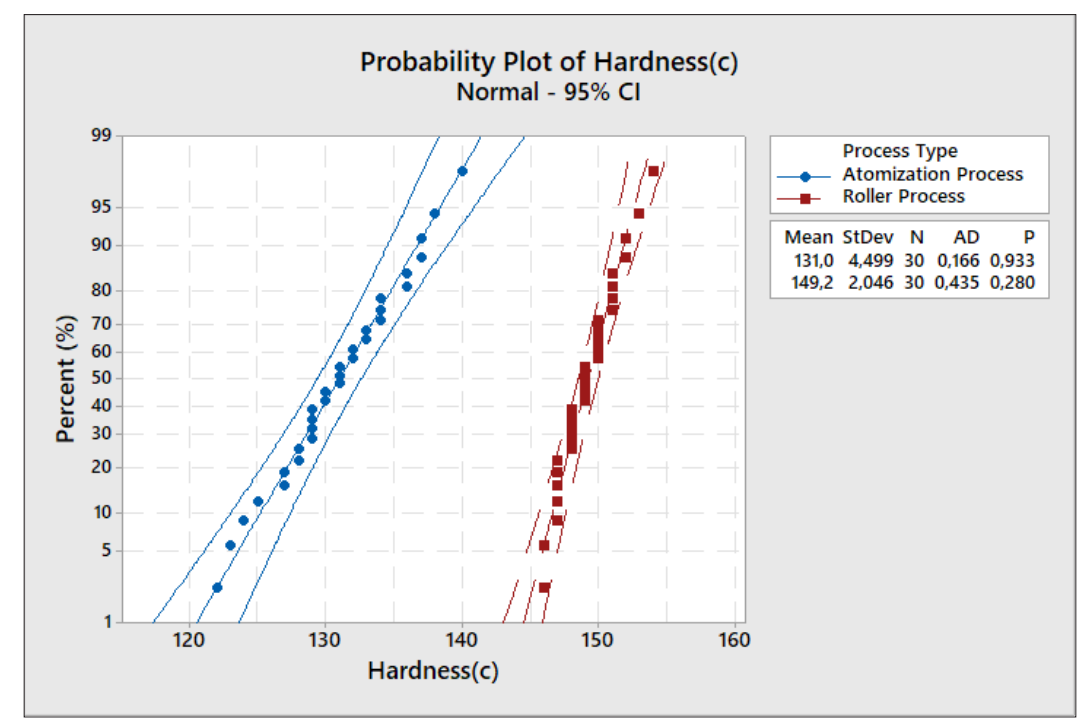

Figure 2: Probability plot results for coating hardness values.

Probability plot results of layer thickness values for roller and atomization processes are displayed in Figure 3. Roller and atomization process mean values for layer thickness were $232,2 \mu \mathrm{m}$ and $151,2 \mu \mathrm{m}$, respectively. 


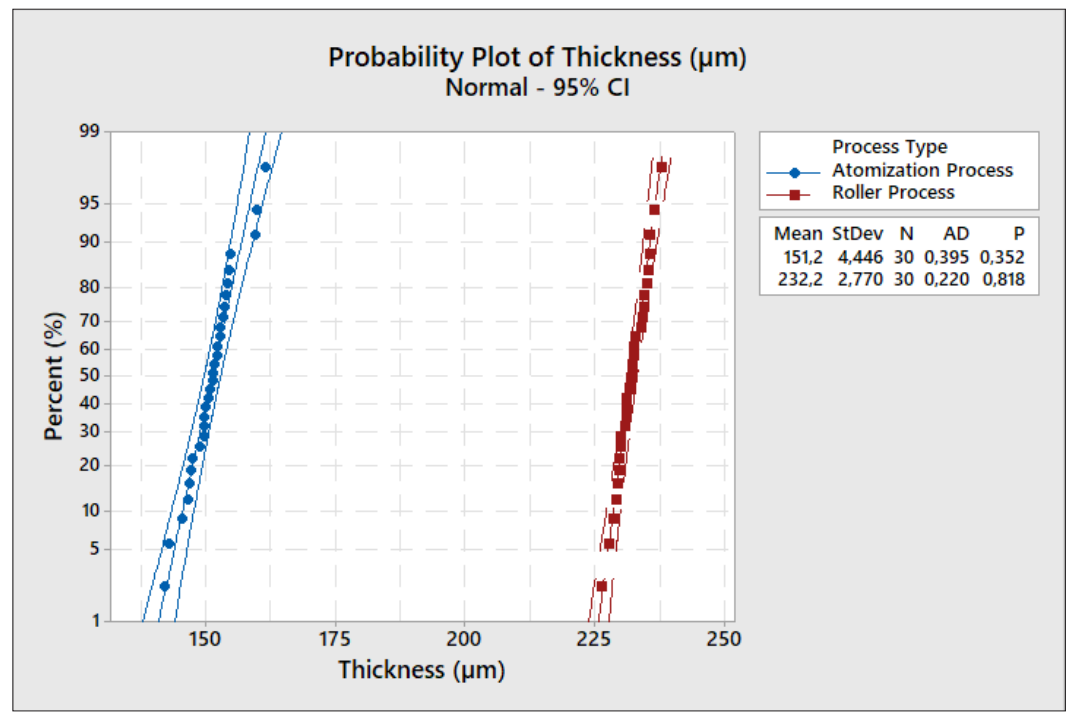

Figure 3: Probability plot results for layer thickness values.

The results of the outlier test are given in Table 3. These values were explained with results of sample size $(\mathrm{N})$, standard deviation (SD), minimum value (Min), maximum value (Max), Grubb's test (G), and P-critical values. At the $5 \%$ level of significance, there were no outlier values for adhesion strength, layer thickness, and coating hardness.

Table 4 shows the p-value was less than 0,05 , displaying the model was significant at a $95 \%$ confidence level. The model terms were statistically evaluated by the F-test at probability levels $(p<0,05)$, degrees of freedom (DF), adjusted sums of squares (Adj SS), and adjusted mean squares (Adj MS). $\mathrm{R}^{2}$ and Adj-R ${ }^{2}$ values for adhesion strength were $80,53 \%$ and $80,20 \%$, respectively. $\mathrm{R}^{2}$ and Adj- $\mathrm{R}^{2}$ values for coating hardness were $87,60 \%$ and $87,39 \%$, respectively. $\mathrm{R}^{2}$ and $\mathrm{Adj}-\mathrm{R}^{2}$ values for layer thickness were $97,20 \%$ and $96,18 \%$, respectively.

Table 3: Results of outlier test for adhesion strength, coating hardness, and layer thickness.

\begin{tabular}{|c|c|c|c|c|c|c|c|c|}
\hline $\begin{array}{c}\text { Quality } \\
\text { Characteristics }\end{array}$ & Variables & $\mathbf{N}$ & Mean & SD & Min & Max & G & P \\
\hline \multirow{2}{*}{$\begin{array}{c}\text { Adhesion } \\
\text { strength }\end{array}$} & $\begin{array}{c}\text { Roller } \\
\text { process }\end{array}$ & 30 & 2,87 & 0,21 & 2,50 & 3,39 & 2,45 & 0,303 \\
\cline { 2 - 9 } & $\begin{array}{c}\text { Atomization } \\
\text { process }\end{array}$ & 30 & 2,07 & 0,18 & 1,74 & 2,38 & 1,77 & 1,000 \\
\hline \multirow{2}{*}{$\begin{array}{c}\text { Coating } \\
\text { hardness } \\
\text { process }\end{array}$} & 30 & 149,23 & 2,05 & 146,00 & 154,00 & 2,33 & 0,448 \\
\cline { 2 - 9 } & $\begin{array}{c}\text { Atomization } \\
\text { process }\end{array}$ & 30 & 130,97 & 4,50 & 122,00 & 140,00 & 2,01 & 1,000 \\
\hline \multirow{2}{*}{ Layer thickness } & $\begin{array}{c}\text { Roller } \\
\text { process }\end{array}$ & 30 & 232,19 & 2,77 & 226,30 & 237,90 & 2,12 & 0,838 \\
\cline { 2 - 9 } & $\begin{array}{c}\text { Atomization } \\
\text { process }\end{array}$ & 30 & 151,20 & 4,45 & 142,10 & 161,40 & 2,29 & 0,502 \\
\hline
\end{tabular}


Table 4: ANOVA Analysis for adhesion strenght, coating hardness and layer thickness.

\begin{tabular}{|c|c|c|c|c|c|c|}
\hline $\begin{array}{c}\text { Quality } \\
\text { Characteristics }\end{array}$ & Source & DF & Adj SS & Adj MS & F-value & P-value \\
\hline \multirow{4}{*}{$\begin{array}{c}\text { Adhesion } \\
\text { strength }\end{array}$} & $\begin{array}{c}\text { Process } \\
\text { type }\end{array}$ & 1 & 9,57 & 9,58 & 239,94 & 0,000 \\
\cline { 2 - 7 } & Error & 58 & 2,32 & 0,04 & & \\
\cline { 2 - 7 } & Total & 59 & 11,89 & & & \\
\hline \multirow{4}{*}{$\begin{array}{c}\text { Coating } \\
\text { hardness }\end{array}$} & $\begin{array}{c}\text { Process } \\
\text { type }\end{array}$ & 1 & 5005,10 & 5005,07 & 409,83 & 0,000 \\
\cline { 2 - 7 } & Error & 58 & 708,30 & 12,21 & & \\
\cline { 2 - 7 } & Total & 59 & 5713,40 & & & \\
\hline \multirow{4}{*}{$\begin{array}{c}\text { Layer } \\
\text { thickness }\end{array}$} & Process & 1 & 98390,70 & 98388,60 & 7170,03 & 0,000 \\
\cline { 2 - 7 } & Error & 58 & 795,90 & 13,70 & & \\
\cline { 2 - 7 } & Total & 59 & 99186,60 & & & \\
\hline
\end{tabular}

Table 5 shows the Tukey method results for adhesion strength, coating hardness, and layer thickness. The model terms were statistically evaluated by the sample size $(\mathrm{N})$, mean, and grouping. According to the results, adhesion strength, coating hardness, and layer thickness values in the roller process were better than the atomization process.

Table 5: Tukey method results for adhesion strength, coating hardness, and layer thickness.

\begin{tabular}{|c|c|c|c|c|}
\hline $\begin{array}{c}\text { Quality } \\
\text { Characteristics }\end{array}$ & Process Type & $\mathrm{N}$ & Mean & Grouping \\
\hline \multirow{2}{*}{$\begin{array}{c}\text { Adhesion } \\
\text { strength }\end{array}$} & Roller & \multirow{2}{*}{30} & 2,87 & $\mathrm{~A}$ \\
\cline { 2 - 3 } \cline { 4 - 4 } & Atomization & & 2,07 & $\mathrm{~B}$ \\
\hline Layer hardness & Roller & \multirow{2}{*}{30} & 149,23 & $\mathrm{~A}$ \\
\cline { 2 - 3 } & Atomization & & 130,96 & $\mathrm{~B}$ \\
\hline \multirow{2}{*}{$\begin{array}{c}\text { Layer } \\
\text { thickness }\end{array}$} & Roller & \multirow{2}{*}{30} & 232,18 & $\mathrm{~A}$ \\
\cline { 2 - 3 } \cline { 4 - 5 } & Atomization & & 151,19 & $\mathrm{~B}$ \\
\hline
\end{tabular}

\section{Evaluation of the adhesion strength, layer thickness, and coating hardness model}

Assumption of normality and histogram of residuals were used to evaluate the experimental data. According to Figure 4a, Figure 4b, Figure 4c, Figure 4d, Figure 4e, and Figure 4f, residuals generally fall on a straight line, implying the residuals resembled the normal distribution. This means that it shows the normal distribution obtained for the evaluation of adhesion resistance, film thickness and film hardness.

When the results obtained as a result of the study are evaluated together with the literature studies, it is seen that the results are supportive. Especially, the effects of the paint applied with both different systems (roller and conventional) on the surface coating performance are similar to the literature studies. 
(a)

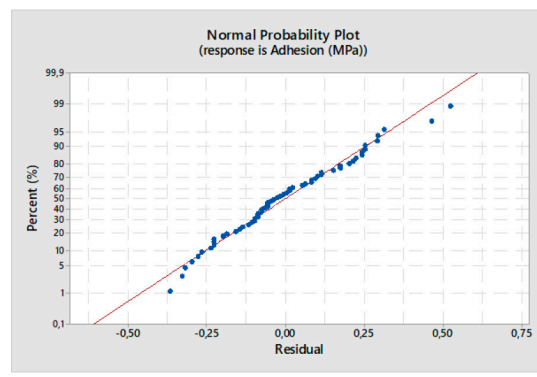

(c)

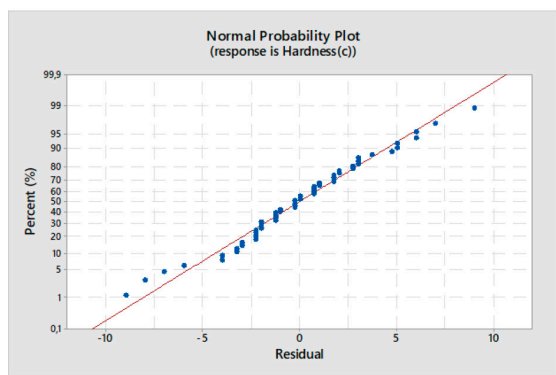

(e)

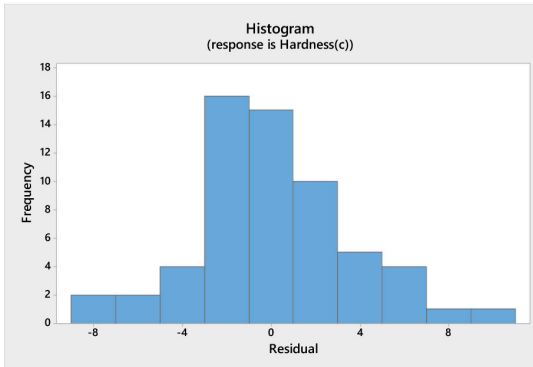

(b)

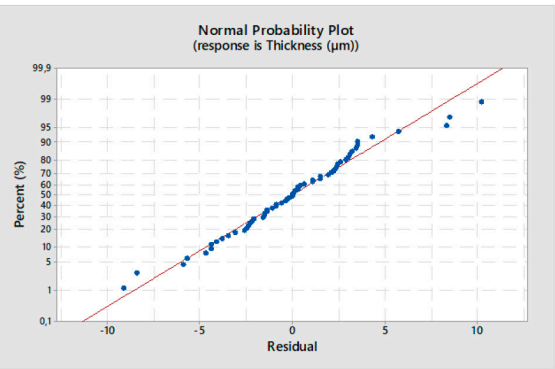

(d)

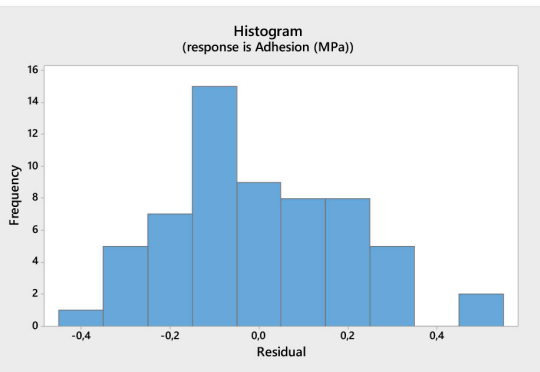

(f)

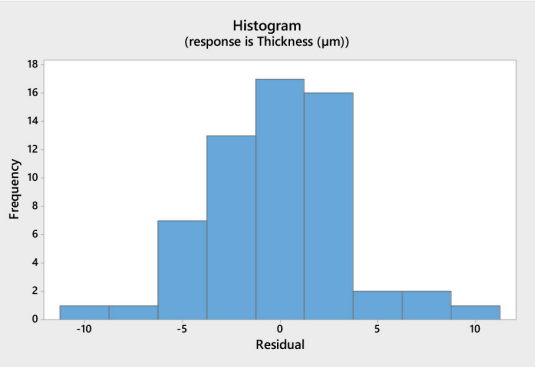

Figure 4: (a), (b), and (c) Normal probability plot for standardized residuals, and (d), (e), and (f) histogram of residuals.

\section{CONCLUSIONS}

In this study, MDF samples were prepared with different coating process namely, roller coater and atomization process. Adhesion strength, surface coating hardness and layer thickness were selected as quality characteristics. These quality characteristics were used to evaluate the surface coating performance. The results are as follows:

According to the ANOVA results, coating process type was the significant factor on strength adhesion, layer thickness, and surface coating hardness. $\mathrm{R}^{2}$ and Adj- $\mathrm{R}^{2}$ values for adhesion strength were $80,53 \%$ and $80,20 \%$, respectively. $\mathrm{R}^{2}$ and Adj- $\mathrm{R}^{2}$ values for coating hardness were $87,60 \%$ and $87,39 \%$, respectively. $\mathrm{R}^{2}$ and $\mathrm{Adj}-\mathrm{R}^{2}$ values for layer thickness were $97,20 \%$ and $96,18 \%$, respectively.

These results were verified using a normal probability plot and histogram of residuals. The model was not any violation of the independence or constant variance assumption, so the model was adequate.

The highest layer thickness value was in the roller coating process, while the lowest layer thickness was in the atomization process. This was due to the UV paint having a higher solid content ratio than the polyurethane paint. Additionally, the transfer efficiency ratio in the roller coating process was better than in the atomization coating system. 
Adhesion strength and coating hardness in the roller coating process were better than in the atomization coating process. This can be explained as follows: (1) The paints used in accordance with the processes had different chemical structures. (2) UV-curable paint was used for the primer coating applications in accordance with the roll system, while the paints used in the atomization coating process were not UV-curable.

\section{ACKNOWLEDGMENTS}

This research was joint funded by TUBITAK (The Scientific and Technological Research Council of Turkey). The authors would like to thank TUBITAK for their support and contributions. The data of this study was obtained from the Ph.D. thesis titled "Integration of Experimental Design and Artificial Intelligence Models to Optimize Wood Surface Performance Parameters". The Grant Number is 1649B031500905.

\section{REFERENCES}

Acda, M.N.; Devera, E.E.; Cabangon, R.J.; Ramos, H.J. 2012. Effects of plasma modification on adhesion properties of wood. Int $J$ Adhes Adhes 32: 70-75. https://doi.org/10.1016/j.ijadhadh.2011.10.003

Ahola, P. 1995. Adhesion between paint and wood substrate: Effects of pre-treatments and weathering of wood. Mater Struct 28: 350. https://doi.org/10.1007/BF02473151

Altigen, M.; Militz, H. 2017. Thermally modified Scots pine and Norway Spruce wood as substrate for coating systems. J Coat Technol Res 14: 531-541. https://doi.org/10.1007/s11998-016-9871-8

Bulian, F.; Graystone, J.A. 2009. Wood Coatings: Theory and Practice. Elsevier: Amsterdam, Netherlands. https://doi.org/10.1016/B978-0-444-52840-7.X0001-X

Cool, J.; Hernández, R.E. 2011. Improving the sanding process of black spruce wood for surface quality and water-based coating adhesion. Forest Prod J61(5): 372-380. https://doi.org/10.13073/0015-7473-61.5.372

Dilik, T.; Erdinler, S.; Hazir, E.; Koç, H.; Hiziroglu, S. 2015. Adhesion strength of wood based composites coated with cellulosic and polyurethane paints. Adv Mater Sci Eng Article ID 745675. https://doi.org/10.1155/2015/745675

Erdinler, S.; Koç, K.H.; Dilik, T.; Hazir, E. 2019. Layer thickness performances of coating on MDF: Polyurethane and cellulosic paints. Maderas-Cienc Tecnol 21(3): 317-326. https://doi.org/10.4067/S0718$221 X 2019005000304$

Gobakken, L.R.; Westin, M. 2008. Surface mould growth on five modified wood substrates coated with three coating different systems when exposed outdoors. Int Biodeter Biodegr 62(4): 397-402. https://doi.org/10.1016/j.ibiod.2008.03.004

Gurleyen, L.; Ayata, U.; Esteves, B.; Cakıcier, N. 2017. Effect of heat treatment on the adhesion strength, pendulum hardness, surface roughness, color and glossiness of Scots pine laminated parquet with two different types of varnish application. Maderas-Cienc Tecnol 19(2): 213-224. http://dx.doi.org/10.4067/S0718-221X2017005000019

Hazir, E. 2018. Integration of Experimental Design and Artificial Intelligence Models to Optimize Wood Surface Performance Parameters, Ph.D. Thesis, Istanbul University -Cerrahpasa, Istanbul, Turkey.

Hazir, E.; Koc, K.H.; Baray, S.A.; Esnaf, S. 2020. Improvement of adhesion strength for woodbased material coating process using design of experiment methodology. Eur J Wood Prod 78: 301-312. https://doi.org/10.1007/s00107-020-01510-3

De Hernandez, R.E.; Cool, J. 2008. Evaluation of three surfacing methods on paper birch wood relation to water and solvent borne coatings performance. Wood Fiber Sci 40: 459-469. https://wfs.swst.org/index.php/wfs/article/view/1185 
Jocham, C.; Schmidt, T.W.; Wuzella, G.; Teischinger, A.; Kandelbauer, A. 2011. Adhesion improvement of powder coating on medium density fiberboard (MDF) by thermal pre-treatment. J Adhes Sci Technol 25(15): 1937-1946. https://doi.org/10.1163/016942410X537189

Keskin, H.; Tekin, A. 2011. Abrasion resistance of cellulosic, synthetic, polyurethane, waterborne and acid hardening varnishes used woods. Constr Build Mater 25(2): 638-643. https://doi.org/10.1016/j.conbuildmat.2010.07.028

Landry, V.; Blanchet, P.; Cormier, L.M. 2013. Water-based and solvent-based stains: Impact on the grain raising in Yellow Birch. BioResources 8(2): 1997-2009. https://bioresources.cnr.ncsu.edu/resources/water-based-and-solvent-based-stains-impact-on-the-grain-raising-in-yellow-birch/

Minitab. 2019. Minitab Statistical Software version 19. Minitab Inc., State College: PA, USA. https://www.minitab.com/

Moura, L.F.; Hernandez, R.E. 2006. Effects of abrasive mineral, grit size and feed speed on the quality of sanded surfaces of sugar maple wood. Wood Sci Technol 40: 517-530. https://doi.org/10.1007/s00226-0060070-0

Nejad, M.; Cooper, P. 2011. Exterior wood coatings. Part-2: Modeling correlation between coating properties and their weathering performance. J Coat Technol Res 8: 459-467. https://doi.org/10.1007/s11998-011-9331-4

Nejad, M.; Ung, T.; Cooper, P. 2012. Effect of coatings on ACQ preservative component distribution and solubility after natural weathering exposure. Wood Sci Technol 46: 1169-1180. https://doi.org/10.1007/s00226-012-0472-0

Plesniak, M.W.; Sojka, P.E.; Singh, A. K. 2004. Transfer efficiency for airless painting system. $J$ Coat Technol Res 1: 137-145. https://doi.org/10.1007/s11998-004-0008-0

Ramananantoandro, T.; Eyma, F.; Belloncle, C.; Rince, S.; Irle, M. 2017. Effect of machining parameters on raised grain occurring after the application of water-based finishes. Eur J Wood Prod 76:1323-1333. https://doi.org/10.1007/s00107-017-1250-3

Salca, E.A.; Krystofiak, T.; Lis, B.; Mazela, B.; Proszyk, S. 2016. Some coating properties of black alder wood as function of varnish type and applications method. BioResources 11: 7580-7594. https://doi.org/10.15376/biores.11.3.7580-7594

Salca, E.A.; Krystofiak, T.; Lis, B. 2017. Evaluation of selected properties of Alder wood as functions of sanding and coating. Coatings 7(10): 176-186. https://doi.org/10.3390/coatings 7100176

Sjökvist, T.; Blom, A. 2019. The influence of coating color, heartwood and sapwood, on moisture content and growth of microorganisms on the surface during outdoor exposure of Norway spruce board. $J$ Coat Technol Res 16: 819-826. https://doi.org/10.1007/s11998-018-00165-3

Söğütlü, C.; Nzokou, P.; Koc, I.; Tutgun, R.; Dönges, N. 2016. The effect of surface roughness on varnish adhesion strength of wood materials. J Coat Technol Res 13: 863-870. https://doi.org/10.1007/s11998016-9805-5

TS EN ISO. 2005. Paints and varnishes- Pendulum damping test. TS EN ISO 1522. 2005. TSE: Ankara, Turkey. https://intweb.tse.org.tr/Yetki/Login/Login.aspx

TS EN ISO. 2019. Paints and varnishes-Determination of film thickness. TS EN ISO 2808. 2019. TSE: Ankara, Turkey. https://intweb.tse.org.tr/Yetki/Login/Login.aspx

TS EN ISO. 2016. Paints and varnishes- Pull-off test for adhesion. TS EN ISO 4624. 2016. TSE: Ankara, Turkey. https://intweb.tse.org.tr/Yetki/Login/Login.aspx

Ugulino, B.; Hernandez, R.E. 2016. Analysis of sanding parameters on surface properties and coating performance of red oak wood. Wood Mater Sci Eng 13(2): 64-72. https://doi.org/10.1080/17480272.2016.12 66511 